\title{
REFLEXÕES TEÓRICAS, POLÍTICAS E METODOLÓGICAS SOBRE UM MORRER, VIRAR E NASCER TRAVESTI NA ADOLESCÊNCIA
}

\author{
Tiago Duque \\ Universidade Estadual de Campinas
}

\begin{abstract}
Resumo: A partir de uma pesquisa com adolescentes travestis da cidade de Campinas, este texto procura refletir a respeito de questões teóricas, políticas e metodológicas que envolvem a temática do gênero e da sexualidade na contemporaneidade. Procura valorizar a necessidade de se estudarem mais as convenções e as normas sociais do que focar no indivíduo em si. Pensa a questão subjetiva e corporal do/da pesquisador/a em contato com os/as interlocutores/ as e problematiza a neutralidade científica em etnografias que envolvem experiências trans. Além disso, contextualiza a reflexão queer e os dilemas que envolvem a produção do conhecimento situado.

Palavras-chave: metodologia; teoria queer; travestis adolescentes.
\end{abstract}

\begin{abstract}
"Pessoal olha que legal... O lançamento do livro que meu amigo Tiago Duque escreveu, ele realizou umas pesquisas comigo, me perguntando várias coisas sobre o meio Trans e o meio GLS, e isso foi parar no livro... me sinto honrada, lembrando que a capa também é uma foto minha :) ameiiii..."

Estudar gênero e sexualidade entre adolescentes é um desafio para qualquer pesquisador/a quando se leva em consideração toda a perseguição erótica que esses sofrem por parte da legislação, por serem classificados como "menores de idade". Como afirmou Gayle Rubin, a lei é implacável ao criar uma fronteira entre a "inocência" da infância e a sexualidade "adulta". Em vez de reconhecer a sexualidade dos jovens e tentar dar-lhe suporte, nossa cultura nega e pune o interesse e a atividade erótica de qualquer pessoa que não atingiu a maioridade. "O volume de disposições legais destinadas a proteger os jovens de um exercício prematuro da sexualidade é espantoso"'. Por isso, para não criar problemas
\end{abstract}

Copyright (c) 2012 by Revista Estudos Feministas.

' Gayle RUBIN, 2003, p. 43. 
(especialmente para elas), procurei não expor as interlocutoras travestis que participaram da pesquisa que resultou em minha dissertação de mestrado em Sociologia, defendida na Universidade Federal de São Carlos. ${ }^{2}$ No entanto, como revela o fragmento acima referente à publicação da pesquisa em formato de livro, retirado de uma página do Facebook de uma das entrevistadas, essa postura metodológica às vezes vai por água abaixo, mesmo usando nomes fictícios e somente uma foto de parte de uma peça de roupa.

O primeiro desafio que enfrentei diante da possibilidade de pesquisar travestis adolescentes foi exatamente este, tomá-las como agentes de suas histórias (sejam quais fossem) sem deixar de pensar em suas estratégias de resistências e também de conformidades com normas e convenções que muitas vezes recaem sobre elas mesmas. Também foi necessário desenvolver um olhar crítico às posturas que buscavam "proteger" essas adolescentes sem valorizar os seus desejos e expectativas de vida. Buscar não olhá-las de forma a vitimizá-las, tão pouco responsabilizá-las pelo que sofrem, foi mais um dos desafios enfrentados em campo. Aspectos como "desconfiar" de certezas êmicas, assumir um referencial teóricopolítico e não deixar de considerar o meu corpo e subjetividade neste estudo foram outros desafios igualmente presentes. Aqui, mais do que expor os resultados da pesquisa, procurarei refletir a respeito das experiências etnográficas, dos referenciais teórico-políticos e das posturas metodológicas no estudo de travestis adolescentes.

\section{A pesquisa}

Para a realização da pesquisa, parti da compreensão de etnografia nos termos de Löic J. D. Wacquant, como sendo a metodologia que exige que o sociólogo faça a imersão iniciática e exercite a

conversão moral e sensual ao cosmo considerado como técnica de observação e de análise que, com a condição expressa de que ela seja teoricamente instrumentada, deve permitir ao sociólogo apropriar-se na e pela prática dos esquemas cognitivos, éticos, estéticos e conativos que põe em operação cotidiana aqueles que o habitam.

Essa metodologia não foi escolhida aleatoriamente, mas a partir da constatação de que somente o convívio junto desses sujeitos, com a ajuda dos referenciais teóricos, poderia oferecer respostas às minhas indagações a respeito dessa cultura sexual na adolescência. Assim, procurei construir o campo, e não tomá-lo como dado.

No entanto, antes do início deste estudo eu já possuía contatos frequentes com a maior parte das interlocutoras. Esses contatos se deram em ações do ldentidade - Grupo de Luta pela Diversidade Sexual, enquanto fui educador social de rua do Programa de Enfrentamento à Exploração Sexual Comercial de Crianças e Adolescentes e durante atividades que dirigi como assessor do Núcleo de Educação e Comunicação Social do Programa Municipal de DST/Aids de Campinas, São Paulo.

Por isso procurei manter uma postura semelhante à da Anna Paula Vencato, quando estudou drags. Ela buscou se questionar o quanto as informações que lhes eram dadas assim o eram por ela ser antropóloga ou por ser amiga das interlocutoras de sua pesquisa. A saída dela foi não usar algumas informações, tanto obtidas em campo como no seu précampo, como "forma de não arrancar a peruca das drags no palco". ${ }^{4}$ No entanto, as

\footnotetext{
${ }^{2}$ A pesquisa foi orientada pelo prof. Dr. Richard Miskolci, ver Tiago DUQUE, 2011.

3 Löic WACQUANT, 2002, p. 12.

${ }^{4}$ Anna Paula VENCATO, 2002, p. 25. O que, segundo esclarece Vencato, é expor a drag à humilhação diante da plateia, descaracterizando sua personagem e desqualificando sua montagem, além de revelar a estranhos (o público) atributos que só deveriam ser expostos no camarim.
} 
informações que coletei por amizade ou por outras relações que criei como militante, assessor governamental e educador social de rua foram usadas como um pano de fundo para a forma como apresentei e analisei os dados. Em outras palavras, elas foram usadas porque seria impossível não considerá-las, no entanto, não foram expostas.

Além disso, o meu Trabalho de Conclusão de Curso, ${ }^{5}$ cujo tema versava sobre a "identidade travesti e a aplicação do silicone líquido", já havia me favorecido uma compreensão inicial bastante densa de parte das experiências das travestis na cidade de Campinas. Portanto, considerando esse histórico junto às travestis, o contato com as interlocutoras para as entrevistas se deu pelo pertencimento delas a determinada rede social para que se garantisse o acesso a um material que pudesse minimizar ou, pelo menos, manter relativamente sob controle (e reflexão) o viés de escolha das entrevistadas. ${ }^{6}$

Entendo rede social como o "conjunto de relações interpessoais concretas que vinculam indivíduos a outros indivíduos"7 e que podem se caracterizar, segundo John A. Barnes, como rede social total ou parcial. A rede social total "é uma abstração de primeiro grau da realidade, e contém a maior parte possível da informação sobre a totalidade da vida social da comunidade à qual corresponde". Já a rede social parcial é entendida como "qualquer extensão de uma rede total, com base em algum critério que seja aplicável à rede social". 8

Nesses termos, trabalhei com redes parciais por ter "isolado" apenas as relações entre travestis adolescentes de suas redes totais, considerando que esse método se caracteriza com a primeira entrevistada indicando as próximas e assim por diante. Porém, não me preocupou atingir uma amostragem quantitativamente grande de sujeitos entrevistados ou observados, porque os grupos tidos como minoritários podem ter uma significação sociológica que ultrapassa em muito sua importância quantitativa. ${ }^{9}$

Essa possibilidade me trouxe surpresas e dados bastantes enriquecedores, não somente porque a ordem das entrevistas foi muito diferente do que eu supostamente teria se tivesse feito as entrevistas aleatoriamente (o que significa que o meu campo seria muito diverso do que eu construí seguindo as indicações), mas também por me levar a algumas adolescentes que jamais teria imaginado entrevistar. Outro fato que essa metodologia me proporcionou foi considerar uma temporalidade e uma espacialidade muito distinta daquela que eu comumente consideraria. Refiro-me ao fato de uma travesti ter sido indicada para participar da pesquisa, mas não ter sobrevivido a tempo de eu me encontrar com ela viva. Nesse caso, somente quando eu estava em seu enterro, e de maneira inesperada, me dei conta de que aquela pessoa que estava ali no caixão era Giselle, a travesti com quem eu tinha entrevista marcada. Esse momento me permitiu analisar a experiência de um "morrer travesti".

A marca de bala na testa de Giselle, sua visível imagem feminina e os seus nomes (de registro e social/masculino e feminino) sendo pronunciados em apelos de desabafos dos familiares e das amigas me fizeram viver um momento de espanto, assim como escreveu Berenice Bento na introdução de seu livro sobre sexualidade e gênero na experiência transexual. Segundo ela, foram muitos os momentos de espanto diante de "corpos que embaralham as fronteiras entre o natural e o artificial, entre o real e o fictício, e que denunciam, implícita ou explicitamente, que as normas de gênero não conseguem um consenso absoluto na vida social". ${ }^{10}$

\footnotetext{
${ }^{5}$ DUQUE, 2005.

${ }^{6}$ Maria Luiza HEILBORN, 2004.

7 John BARNES, 1987, p. 167.

${ }^{8}$ BARNES, 1987, p. 166.

${ }^{9}$ Norbert ELIAS e John SCOTSON, 2000, p. 119.

${ }^{10}$ Berenice BENTO, 2006, p. 19-20.
} 
Com as outras interlocutoras, as entrevistas foram feitas face a face em diferentes locais (shopping center, casa, parque público) e também por Messenger (MSN). Todas elas aceitaram dar entrevistas e me responderam através das mensagens on-line que concordavam em ter seus depoimentos usados no estudo. Além disso, utilizei também o Orkut para trocar mensagens, conhecer comunidades temáticas, assistir a vídeos e ver as fotos postadas.

Foi mais precisamente esses espaços on-line que me favoreceram a compreensão de um "nascer travesti". Pude perceber ao longo do trabalho de campo uma mudança no perfil do Orkut de Daniele, uma das entrevistadas que moravam em Campinas e durante a pesquisa mudou-se para a Europa. As fotografias tiradas em uma noite escura em uma garagem, ou aquelas feitas em um posto de gasolina frequentado principalmente por caminhoneiros, deram pouco a pouco espaço a imagens de praias ensolaradas e paradisíacas. Enquanto Daniele estava no Brasil, em seus álbuns de fotos não havia imagens de paisagens por onde passava ou do local onde morava. Atualmente, podem-se ver fotos de praças, shoppings e edifícios iluminados. Além disso, as fotos de Daniele com pouca roupa em frente a um caminhão, em ambientes com pouca luz, foram substituídas por fotos produzidas em uma linda casa com piscina e outras em estúdio com roupas luxuosas, maquiada e apresentada de maneira a parecer menos negra, além de adornada com joias e sapatos com strasses. Construção que a identifica como uma verdadeira europeia, a categoria êmica mais valorizada no meio travesti por denotar sucesso, enriquecimento e sofisticação. ${ }^{11}$

Foi também através do Orkut de Vagner, um dos adolescentes entrevistados que "gostavam de se montar", que o "virar travesti" me chamou a atenção. As fotografias, os vídeos, os depoimentos e as comunidades me mostravam que ele era fã ativo de duas drags famosas: uma tida como branca, luxuosa e linda e a outra como negra, "penosa"12 e escandalosa. O fato de ele optar em certo momento da pesquisa em não "virar mais travesti" e se transformar em uma drag com o mesmo sobrenome da drag tida como branca, luxuosa e linda me revelou o quanto o glamour ainda se sobrepõe em muitas escolhas nas experiências trans; afinal, os/as amigos/as de Vagner insistiam que ele era muito parecido com a outra drag, a negra.

Matérias jornalísticas que tratavam da realidade de prostituição de travestis em Campinas e documentos, tanto de setores governamentais como do movimento social, também foram analisados. Parte deles ajudou a fundamentar a crítica à ideia da incapacidade afetivo-intelectual que supostamente adolescentes têm em relação à tomada de decisões sobre as suas vidas e relativizar a interpretação de que existe uma necessidade intrínseca de proteção por eles não serem "como as outras crianças e adolescentes" que vivem com suas famílias. Isso foi possível a partir da compreensão do papel do pesquisador diante do pânico que esse tema envolve em certos setores da sociedade.

\section{O papel do/a pesquisador/a}

Em se tratando de adolescência, gênero e sexualidade nas experiências travestis, ou de meninos que se vestem como mulher, parece-me central o entrecruzamento de reiterações e, ao mesmo tempo, transformações de convenções e normas sociais, o que possibilita o surgimento de um pânico moral. ${ }^{13}$ Entendo o conceito de pânico moral como

\footnotetext{
11 Larissa PELÚCIO, 2009.

12 "Penosa" é o mesmo que "sem condições", alguém que não tem dinheiro e precisa de algum tipo de ajuda, que não sustenta uma imagem glamorosa de si.

${ }^{13}$ Stanley COHEN, 1972.
} 
a identificação coletiva de um fenômeno social considerado ameaçador à coletividade, em especial a seus valores e normas, como propôs, na década de 1960, Stanley Cohen.

A política simbólica que estrutura os pânicos morais

costuma se dar por meio da substituição, ou seja, grupos de interesse ou empreendedores morais chamam a atenção para um assunto, porque ele representa, na verdade, outra questão. [...] Todo pânico moral esconde algo diverso e, ao invés de aceitar um temor social como dado, o pesquisador precisa desvelar o que reside por trás do medo ${ }^{14}$

Foi na busca de entender não só o que era temido, mas, principalmente, o que estava por trás do proclamado medo que passei a empreender minhas questões de pesquisa. Chamavam-me atenção na elaboração do projeto de pesquisa todas as intervenções mantidas contra a prostituição de travestis em um bairro da cidade de Campinas, especialmente porque fazia parte da justificativa a necessidade de proteger adolescentes dessa realidade. ${ }^{15}$ Assim, parecia-me necessário focar mais nas normas e nas convenções sociais do que nas experiências identitárias em si.

Então, comecei a problematizar a experiência do "ser adolescente" em relação a esse pânico e descobri que o que se temia eram o incentivo e a visibilidade da experiência travesti na adolescência, e não necessariamente a prostituição na adolescência, mesmo porque as interlocutoras da pesquisa não se viam necessariamente como vítimas. Apenas Gabriela mantinha o discurso contra a prostituição e o fazia de forma contextual e fluida, pois sabia que seria valorizada e legitimada como vítima do mercado do sexo, como, por exemplo, em encontros do movimento social LGBT.

Isso me possibilitou entrar em um processo de desconstrução, tanto da noção naturalizada de uma "identidade adolescente" como de uma "identidade travesti". Assim, com o apoio teórico necessário e os primeiros dados do campo, obtive a compreensão do conceito de "adolescência" fora de um referencial etário fixo e rígido (presente no Estatuto da Criança e do Adolescente, por exemplo). Pelo contrário, fazia-me reconhecer que a adolescência em nossa sociedade "vem se tornando um período cada vez mais longo e mais complexo", ${ }^{16}$ revelando o quão socialmente construída é essa categoria. Nessa perspectiva, procurei não focar aspectos biologicistas da experiência do "ser adolescente" que marcam outros estudos e legislações. ${ }^{17}$ Tomei o "ser adolescente" como um conceito autodefinidor desses sujeitos, atentando-me para a categoria "adolescente" especialmente quando ela era utilizada pelos sujeitos entrevistados para se autorreferir, independentemente dos registros legais oficiais. Assim, o que comumente em campo era classificado ou desclassificado baseado em fatores externos (documentos) passou a ser reconhecido na pesquisa como autoidentificação.

\footnotetext{
${ }^{14}$ Richard MISKOLCl, 2007, p. 114.

${ }^{15}$ Entre as intervenções podem-se destacar a dos moradores que chegaram a fotografar as placas dos carros dos clientes e divulgar na internet (Gilson REI, 2003) e o fato de a Câmara dos Vereadores aprovar uma moção que "requer providências das polícias civil e militar em Campinas para a retirada de travestis da região do bairro Bosque dos Jequitibás" (CAMPINAS, 2003).

${ }^{16}$ Daniel BECKER, 1986, p. 12

${ }^{17}$ Contudo, entendo, como outros autores (Cecília COIMBRA, Fernanda BOCCO e Maria Lívia do NASCIMENTO, 2005; e Jane FELIPE, 2006), que, apesar de criticarmos o ECA por pautar a noção de adolescência como período universal, essa legislação é, ainda hoje, um importante instrumento de garantia de inúmeros direitos e de contraposição às campanhas conservadoras que pregam, entre outras reivindicações, o endurecimento de penas, a redução da idade penal e a implantação de uma política de tolerância zero àqueles sujeitos vistos como "menores infratores".

${ }^{18}$ Márcia OCHOA, 2004, p. 254.
} 
Do ponto de vista da compreensão da sexualidade, segui o modelo construtivista, o qual se desenvolveu nas últimas décadas nas ciências sociais e humanas em vertentes teóricas que compreendem a sexualidade como construção social e histórica, como apontam os estudos de Michel Foucault. A filiação deste estudo a uma perspectiva foucaultiana também se deu informada pelas inovações que sua obra suscitou nos estudos norteamericanos sobre sexualidade a partir do final dos anos 1980, ou seja, pela teoria queer. O queer é uma categoria local estadunidense que pode significar excêntrico, esquisito, diferente, bem como o pervertido sexual, marginal, estigmatizado ou anormal. Ela viajou muito, mediante a hegemonia teórica que permite publicação e circulação de textos estadunidenses por todo o mundo, mas não tem a mesma ressonância nos outros lugares. Nesse sentido, Márcia Ochoa propõe chamar a atenção para as nossas próprias categorias locais de rechaço social em vez de buscarmos traduções de queer. Ganharíamos mais em exercícios investigativos que atentassem para nossos próprios xingamentos, seus próprios escândalos e as questões locais em que eles se inserem. ${ }^{18}$ Essa consideração foi essencial não somente para afinar o meu olhar no campo a partir da teoria, mas também para fazer um uso criativo dela, considerando inclusive o diálogo dessa com outros referenciais teóricos surgidos no Brasil, por exemplo, no mesmo momento em que ela estava sendo nomeada nos EUA.

É o caso de Néstor Perlongher, com a sua clássica etnografia feita em São Paulo sobre a experiência dos michês, no final da década de 1980. Hoje, assim como no período em que ele realizou o seu estudo, a entrada na prostituição não é mero resultado da impossibilidade de acesso aos "paradigmas da normalidade", como as realidades de pobreza e preconceito. ${ }^{19} \mathrm{O}$ seu estudo aponta para os itinerários da prostituição como expressão da recusa desses paradigmas de normalidade. Rodrigo, por exemplo, em determinada situação resistiu a ser abrigado para "se recuperar das drogas", porque se via como feminino e a única opção de "acolhimento e proteção" era um abrigo exclusivo para meninos. É nesse sentido que Judith Halberstam afirma que há usos queer de espaço e tempo que se desenvolvem em oposição à família, à heterossexualidade e à reprodução, apontando para experiências fora de marcadores sociais naturalizados como a sucessão (verdadeiro script incentivado socialmente) de nascimento, casamento, reprodução e morte.$^{20}$

Ainda que visibilizar e analisar as experiências de adolescentes fora dos paradigmas da normalidade tenha me colocado algumas vezes como alguém a quem se tem que desconfiar devido a possíveis "segundas intenções", o maior problema em relação a essa teoria foi em relação ao meu histórico no movimento social e na área governamental de prevenção às DSTs/Aids. Afinal, parte do movimento social LGBT tem criado uma interpretação de que vivemos em um momento de separação/oposição entre "queer" e "identitários", isto é, "acadêmicos" e "ativistas". ${ }^{21}$ Essa suposta separação é bastante sintomática à resistência desse grupo à criação de um diálogo mais crítico com o Estado, às pressões conformistas do mercado e, sobretudo, demonstra a crescente desconfiança de vários ativistas com relação à universidade, que tem sido encarada como "competidora" pela representação política ou de demandas dentro de uma agenda de política sexual em manutenção. ${ }^{22}$ Isso tem relação direta com a história do movimento queer nos EUA e a mudança na perspectiva

19 Néstor PERLONGHER, 1987, p. 204.

20 Judith HALBERSTAM, 2005.

${ }^{21}$ Esta suposta separação foi visibilizada de forma polêmica em dois eventos de cunho nacional, no Stonewall 40 + o que no Brasil?, realizado em Salvador pelo Grupo de Pesquisa em Cultura e Sexualidade - CUS, e no VIII Encontro Nacional Universitário de Diversidade Sexual, organizado pelo Grupo Identidade e outros parceiros, cujo tema foi "Assimilação x transformação - políticas da subversão e ciladas dos movimentos sociais". Ambos ocorreram no ano de 2010.

22 MISKOLCl, 2011 , p. 45. 
de interpretação e análise das experiências de gênero e sexualidade não heterossexuais, assim como com a forma como o movimento social LGBT tem se organizado no Brasil. ${ }^{23}$

\section{Teoria e política}

Desde sua origem no contexto norte-americano de fins da década de 1980, a teoria queer propõe alterar o foco de uma exclusiva preocupação com a opressão e a libertação dos sujeitos homossexuais para a análise das práticas institucionais, da produção dos conhecimentos sobre a sexualidade e do modo como eles organizam a vida social. Busca atentar, em particular, para o modo como esses conhecimentos e práticas sociais oprimem diferenças, ${ }^{24}$ ou seja, desfocar análises de sujeitos "anormais" para as normas sociais que os constituem como tal. É por isso que os estudos de Foucault e parte dos estudos feministas são os aportes inspiradores dessa teoria.

Segundo Richard Miskolci e Larissa Pelúcio, a teoria queer procura apontar e compreender o conflito entre os sujeitos e a ordem de gênero vigente. Nessa perspectiva o

compromisso político é o de evidenciar a produção de diferentes identidades não categorizáveis e a necessidade de mudar o repertório existente para que os indivíduos qualificados como menos-humanos, perseguidos, até mesmo assassinados, possam encontrar um mundo habitável e mais acolhedor. ${ }^{25}$

Considerando que essa filiação teórica me possibilitava reconhecer como objeto de pesquisa sujeitos com uma identidade sem essência, sempre ambíguos e relacionais, mas especialmente alargar o olhar para além dos sujeitos e focar nas normas que permeiam suas experiências constitutivas ${ }^{26} \mathrm{~m}$ muitos contextos, era inevitável deixar de fazer a crítica em relação não somente à "identidade travesti", mas também à "identidade LGBT". Essas categorias identitárias não devem ser tomadas como "verdades", seja no âmbito da pesquisa acadêmica, na luta por políticas públicas ou nos contextos de aplicação de ações governamentais. Em outras palavras, no mundo da vida, não encontramos a mulher, o gay, a lésbica, a transexual. "Essas marcas identitárias são abertas e problematizadas. Há certo consenso entre os/as pesquisadores/as brasileiros/as em apontar a pluralidade interna a cada identidade". 27

É nesse sentido que em espaços tidos como sendo do movimento social eu era visto como tendo "ideias muito acadêmicas", vistas como ameaçadoras à pauta política "dos LGBTs"; em alguns espaços de atividade acadêmica e em espaços de organizações governamentais fui visto como "muito militante" por partir de uma análise situada politicamente nas críticas às identidades.

Por outro lado, é inevitável que o fato de ter me aproximado das travestis como sendo "quase uma delas", isto é, era visto também como uma "bicha assumida", uma "amiga", me facilitou o trânsito e a acolhida por parte delas. No entanto, isso não me legitima nem deslegitima como pesquisador. É o que também ressalta Marco Aurélio da Silva em sua "etnografia do carnaval no pedaço GLS da llha de Santa Catarina":

Compartilhar da mesma orientação sexual e tendo participado do carnaval junto de meus entrevistados, talvez seja tão problemático quanto o fato de que somos brasileiros

\footnotetext{
${ }^{23}$ Sobre isso, ler MISKOLCl, 2011.

24 Steven SEIDMAN, 1996, p. 13.

${ }^{25}$ MISKOLCl e PELÚCIO, 2006, p. 265.

${ }^{26} \mathrm{MISKOLCl}, 2009$.

${ }^{27}$ BENTO, 2011 , p. 80.
} 
e que compartilhamos o mesmo idioma cultural. Desta forma, o que me credencia a estudar entre mulheres surfistas ou entre catarinenses que precisam conviver com hidrelétricas? E mais: por que nunca se questionam o fato de homens e mulheres que se entendem como "heterossexuais" estudarem outros "heterossexuais"?

Érica Souza, por sua vez, ao propor pesquisar em seu projeto de doutorado a questão da maternidade lésbica no Brasil e no Canadá, enfrentou um problema inverso e fez uma reflexão bastante pertinente a esse respeito. Não se identificando como militante, lésbica nem como mãe, a pesquisadora demorou a se aproximar, no Canadá, daqueles que precisava entrevistar. Esse fato a incomodou porque

1) a dualidade queer e não queer não resolve o problema da legitimidade do discurso do pesquisador, porque mesmo dentro da categoria queer várias definições são feitas, e cada componente da sigla GBLT ocupa um lugar distinto social e politicamente, bem como dentro da "pesquisa queer"; 2) na pesquisa antropológica não queremos falar por, mas sobre, segundo nossa observação e perspectiva subjetiva. ${ }^{29}$

Mas também passei por certas "saias justas" em relação a algumas "cantadas" por parte de travestis, inclusive de adolescentes, por desconfiarem do meu "grau de viadagem". Nesse caso, a categoria "marido" ou "namorado" também foi usada em campo dirigida a mim, esperando que eu pudesse "morder a isca". De certa forma, o mesmo se passou com outros pesquisadores, como Marcos Benedetti ${ }^{30}$ e Mário Felipe de Lima Carvalho. ${ }^{31}$ Penso que isso seja "natural", não por se tratar de travestis, mas por tomar como certo que o desejo, seja o nosso ou o dos outros, não deixa de estar presente em nossas atividades, inclusive nas de pesquisas.

\section{Campo, corpo e subjetividade}

Segundo Crístian Paiva, "Não é raro que os trabalhos no campo de estudos de gênero e sexualidade mobilizem todas as dimensões da subjetividade do pesquisador, num imperativo de (auto-)reflexividade às vezes excruciante". ${ }^{32} \mathrm{Em}$ seu trabalho de pesquisa desenvolvido em um caraoquê numa sauna gay em Fortaleza, percebeu que comumente, quando se trata desse temas, há uma inquisição moral das "reais intenções" do pesquisador (como já citei ter passado) e, além disso, existem também

os desafios relativos aos procedimentos metodológicos e ao lugar do pesquisador na produção de conhecimento situado - negociações de aceitação e inserção no campo, que envolvem, muito freqüentemente uma disponibilidade para expor-se, mostrar seu próprio corpo, até o ponto em que o grupo estudado não se dê mais conta de que há ali um "estranho no ninho".

Então, o desafio não é somente em um suposto campo estritamente intelectual, mas também pessoal-corporal-subjetivo. Camilo Albuquerque Braz faz o mesmo apontamento quando descreve o seu corpo nu no campo durante os estudos em clubes de sexo para homens. Para ele, a experiência corporal, não só dos sujeitos estudados, mas também de quem é o responsável pelo estudo, pode ser alçada à categoria de método de pesquisa.

\footnotetext{
${ }^{28}$ Marco Aurélio da SILVA, 2003, p. 10.

29 Érica Renata de SOUZA, 2005, p. 33.

${ }^{30}$ Marcos BENEDETTI, 2000.

${ }^{31}$ Mário Felipe de Lima CARVALHO, 2011.

${ }^{32}$ Antonio Crístian Saraiva PAIVA, 2009, p. 13.

${ }^{33}$ PAIVA, 2009, p. 13.
} 
Não se trata aqui de jogar fora a possibilidade do distanciamento, nem de "virar nativo". Mas de levar em conta o quanto a realidade estudada pode ser incorporada não só nos sujeitos da pesquisa, mas também no/a próprio/a pesquisador/a. ${ }^{34}$

Essa percepção me pareceu fundamental nos estudos de travestis desde a minha primeira inserção no campo, ainda na graduação em Ciências Sociais. Na primeira atividade junto às travestis do grupo Identidade, fui pego de surpresa e o meu corpo foi usado como "boneco" para que elas montassem o que compreendiam ser um "homossexual". Surgi pela primeira vez de peça íntima diante de aproximadamente 15 travestis, que me observavam com atenção e que, a partir daquele instante, também se tornariam motivo de minha observação. ${ }^{35}$

Essa visibilidade e percepção do corpo do pesquisador foram fundamentais para a continuidade da imersão no campo e a confiabilidade necessária de parte das interlocutoras para a realização da pesquisa. Outra situação ocorreu durante a elaboração do projeto de pesquisa para o mestrado: era madrugada, eu e uma amiga travesti estávamos em um bar no qual havia muitos adolescentes ("boyzinhos") e outras travestis. 0 Estado em sua função "protetiva" entrou no bar representado por muitos policiais fortemente armados e separou os adultos (nesse caso, as travestis e outros gays mais idosos) dos "menores". Em virtude de eu estar do lado de uma travesti, para mim foi pedido o documento de identidade, como estava sendo solicitado para todos os supostamente adolescentes e não para os adultos. Depois de conferirem rapidamente a minha data de nascimento e não checarem qualquer outro dado, fui "liberado". Mais tarde descobrimos que a "operação" era devido a denúncias de que ali havia abuso sexual contra adolescentes. Ter passado pela suspeita de ser um "menor" sendo vítima de uma travesti foi motivo de risos por parte delas e depois de reflexão quando iniciei o campo propriamente dito.

É nesse sentido que o corpo permite a experiência de ser ele mesmo, o pesquisador, a realidade estudada. Mas, atualmente, em minha pesquisa de doutorado, tenho feito uma reflexão ainda inicial sobre o fato de o meu corpo não só fazer parte, mas também criar o fenômeno ou a experiência que tenho pesquisado. Buscando compreender as situações e os contextos (suas normas e convenções) das experiências trans que lhes permitem "passar por mulher", em uma das minhas primeiras entrevistas ouvi de uma transexual que, por exemplo, se ela estiver conversando comigo na rua e passar alguém e vir, vai ser mais fácil ela "passar por mulher", porque o meu corpo (e esse meu "jeito") denuncia que eu sou masculino e que ela é feminina. É nesse sentido que eu crio o contexto e a situação (o que tenho pesquisado) que permitem a ela "ser passável" aos olhos de quem nos vê juntos.

Não é à toa que Berenice Bento afirma que "a/o travesti e a/o transexual construído como outro, o estranho, propicia uma profunda desconstrução da subjetividade do/da pesquisador/a".

É um processo duplo de humanização: de um lado, descobrimos que somos feitos do mesmo material discurso e que a noção de margem e centro funciona precariamente para delimitar os processos tensos de constituição das identificações. E, segundo, o/a pesquisador/a quebra esquemas mentais que the informam sobre noções de normalidade e anormalidade. Nesse jogo, "sua" (aspas são para marcar um campo de desconfiança com a noção de propriedade que temos do eu) própria subjetividade, corpo, sexualidade, gêneros e projetos de vida se veem na berlinda. ${ }^{36}$

${ }^{34}$ Camilo Albuquerque BRAZ, 2009, p. 91.

${ }^{35}$ DUQUE, 2005.

${ }^{36}$ BENTO, 2011 , p. 85. 
Por isso, segundo ela, têm sido frequentes no Brasil e em outros países estudos que cruzam todos os limites da neutralidade científica, em que os/as pesquisadores/as são ganhos para a práxis a partir do campo de pesquisa. É a partir dessa perspectiva que finalizo problematizando os usos do termo "travestilidade" como um exemplo de o quanto já não é mais possível (se é que em algum momento o foi) se esquivar das implicações políticas das nossas produções teóricas.

Segundo Bruno Cesar Barbosa, esse termo aponta para as conexões entre as formulações acadêmicas e as demandas dos sujeitos (militantes ou não), por ele estar sendo usado pelas próprias interlocutoras a partir do que tem sido escrito pelos/as pesquisadores/as.

Desde os contextos iniciais dos seus usos, o termo "travestilidade" indica a multiplicidade de possibilidades das experiências travestis. ${ }^{37}$ Mas, para Barbosa, "o uso do termo travestilidade como conceito analítico pode implicar o risco de homogeneizar esta diversidade de oposições". ${ }^{38}$ Sua crítica está baseada em uma interpretação da "etnografia travesti sobre o modelo preventivo de aids", de Larissa Pelúcio. ${ }^{39}$ Segundo ele, ela reduziu a multiplicidade das experiências de travestis por, de forma essencializadora, classificar o "ser travesti" como uma "condição", guiando-se assim pela lógica do próprio grupo. Mas o que mais quero chamar a atenção aqui é que, considerando o argumento de Barbosa, sobrariam poucos conceitos analíticos disponíveis para serem utilizados, afinal sempre estará presente o risco de homogeneizar a diversidade de oposições (por exemplo, nos usos dos termos "homofobia", "identidade", "desejo" e "LGBT"). Assim, não são os termos necessariamente que merecem maior atenção e crítica, mas as formas e as intencionalidades com que eles têm sido usados. Negá-los, deixar de criá-los ou substituí-los não vai nos livrar de posturas simplistas, unilaterais e/ou pouco complexas. Como afirma o próprio autor,

Se a produção de categorias tende a fixar e controlar corpos, tal processo também se abre em possibilidades de usos que não necessariamente se fecham. [...] As formas como tais pessoas se apropriam de tais convenções muitas vezes desafiam sentidos previstos.

É exatamente por isso que a questão da neutralidade precisa ser mantida sobre forte rasura. $E$, se não há como nos livrarmos (e há de se perguntar se queremos) das implicações que nossas teorias vão criar no "mundo da vida", é bom não deixar a intencionalidade de lado, mesmo sabendo que o poder que teremos sobre isso será absolutamente relativo.

Concluo afirmando que a intenção deste texto não foi a de insinuar um "jeito de fazer", mas partilhar caminhos que podem ser tomados como uma possibilidade (entre tantas outras) de serem percorridos, cruzados ou, até mesmo, negados quando nos dispomos a estudar gênero e sexualidade.

\section{Referências}

BARBOSA, Bruno Cesar. Normas e diferenças: uma etnografia dos usos das categorias travesti e transexual. 2010. Dissertação (Mestrado em Antropologia) - Faculdade de Filosofia, Letras e Ciências Humanas, Universidade de São Paulo, São Paulo, 2010.

BARNES, John. "Redes sociais e processo político". In: FELDMAN-BIANCO, Bela (Org.). Antropologia das sociedades contemporâneas: métodos. São Paulo: Global Universitária, 1987. p. 159-189.

${ }^{37}$ Wiliam Siqueira PERES, 2005.

${ }^{38}$ Bruno Cesar BARBOSA, 2010, p. 109.

${ }^{39}$ PELÚCIO, 2009.

${ }^{40}$ BARBOSA, 2010, p. 111-112. 
BECKER, Daniel. O que é adolescência. São Paulo: Nova Cultural; Brasiliense, 1986. (Coleção Primeiros Passos, 78).

BENEDETII, Marcos R. Toda feita: o corpo e o gênero das travestis. 2000. Dissertação (Mestrado em Antropologia Social) - Programa de Pós-Graduação em Antropologia Social, Universidade Federal do Rio Grande do Sul, Porto Alegre, 2000.

BENTO, Berenice. A reinvenção do corpo: sexualidade e gênero na experiência transexual. Rio de Janeiro: Garamond, 2006.

"Política da diferença: feminismos e transexualidades". In: COLLING, Leandro (Org.). Stonewall 40 + o que no Brasil? Salvador: UFBA, 2011. p. 79-110.

BRAZ, Camilo Albuquerque. "Vestido de antropólogo: nudez e corpo em clubes de sexo para homens". Revista Bagoas, UFRN, n. 3, p. 75-95, 2009.

CAMPINAS/SP. Câmara Municipal. Moção n. 93/03, de 19 de novembro de 2003. Requer providência das Polícias Civil e Militar em Campinas para a retirada de travestis da região do Bosque dos Jequitibás. Campinas, SP: Câmara Municipal, 2003.

CARVALHO, Mario Felipe de Lima. "Que mulher é essa?": identidade, política e saúde no movimento de travestis e transexuais. 2011. Dissertação (Mestrado em Saúde Coletiva) Instituto de Medicina Social, Universidade do Estado do Rio de Janeiro, Rio de Janeiro, 2011.

COHEN, Stanley. Folk Devils and Moral Panics: The Creation of Mods and Rockers. London: MacGibbon \& Kee, 1972.

COIMBRA, Cecília C.; BOCCO, Fernanda; NASCIMENTO, Maria Lívia do. "Subvertendo o conceito de adolescência". Arquivos Brasileiros de Psicologia, v. 57, n. 1, p. 2-1 1, 2005. Disponível em: <http://pepsic.bvs-psi.org.br/pdf/arbp/v57n1/v57nla02.pdf>. Acesso em: 10 abr. 2010.

DUQUE, Tiago. Montadas para toda a vida? O uso do silicone líquido na construção da identidade travesti. 2005. Trabalho de Conclusão de Curso (Graduação em Ciências Sociais) - Curso de Bacharelado e Licenciatura em Ciências Sociais, Pontifícia Universidade Católica de Campinas, Campinas, 2005.

. Montagens e desmontagens: desejo, estigma e vergonha entre travestis adolescentes. São Paulo: Annablume, 2011.

ELIAS, Norbert; SCOTSON, John L. Os estabelecidos e os outsiders: sociologia das relações de poder a partir de uma pequena comunidade. Rio de Janeiro: Jorge Zahar, 2000.

FELIPE, Jane. "Afinal, quem é mesmo pedófilo?". Cadernos Pagu, v. 26, p. 201-223, 2006.

HALBERSTAM, Judith. In a Queer Time and Place: Transgender Bodies, Subcultural Lives. New York/London: New York University Press, 2005.

HEILBORN, Maria Luiza. Dois é par: gênero e identidade sexual em contexto igualitário. Rio de Janeiro: Garamond, 2004.

MISKOLCI, Richard. "Pânicos morais e controle social: reflexões sobre o casamento gay". Cadernos Pagu, Campinas: Núcleo de Estudos de Gênero Pagu, n. 28, p. 101-128, 2007. Dossiê Sexualidades Disparatadas.

"O armário ampliado: notas sobre sociabilidade homoerótica na era da internet". Gênero, UFF, v. 9, n. 2, p. 171-190, 2009.

. "Não somos, queremos: reflexões queer sobre a política sexual brasileira contemporânea". In: COLLING, Leandro (Org.). Stonewall 40 + o que no Brasil? Salvador: UFBA, 201 1. p. 37-56.

MISKOLCI, Richard; PELÚCIO, Larissa. "Fora do sujeito e fora do lugar: reflexões sobre performatividade a partir de uma etnografia entre travestis". Gênero, Niterói: Núcleo Transdisciplinar de Estudos de Gênero, UFF, p. 255-267, 2006.

OCHOA, Márcia. "Ciudadanía perversa: divas, marginación y participación en la 'Iocalización'”. In: MATO, Daniel (Coord.). Políticas de ciudadanía y sociedad civil en 
tiempos de globalización. Caracas: FACES, Universidad Central de Venezuela, 2004. p. 239-256. Disponível em <http://www.globalcult.org.ve/pub/Rocky/Libro2/Ochoa.pdf >. Acesso em: 10 abr. 2010.

PAIVA, Antonio Crístian Saraiva. "Pulsão invocante e constituição de sociabilidades clementes: notas etnográficas sobre karaokê numa sauna em Fortaleza". In: ENCONTRO ANUAL DA ANPOCS, 33., 2009, Caxambu. GT 36 Sexualidade, corpo e gênero.

PELÚCIO, Larissa. Abjeção e desejo: uma etnografia travesti sobre o modelo preventivo de aids. São Paulo: Annablume, 2009.

PERES, Wiliam Siqueira. Subjetividade das travestis brasileiras: da vulnerabilidade da estigmatização à construção da cidadania. 2005. Tese (Doutorado em Saúde Coletiva) - Programa de Pós-Graduação em Saúde Coletiva, Universidade Estadual do Rio de Janeiro, Rio de Janeiro, 2005.

PERLONGHER, Néstor. O negócio do michê: prostituição viril em São Paulo. São Paulo: Brasiliense, 1987.

REl, Gilson. "Internet denuncia clientela da prostituição". Correio Popular, Campinas, p. 4, 22 nov. 2003.

RUBIN, Gayle. "Pensando sobre sexo: notas para uma teoria radical da política da sexualidade". Cadernos Pagu, Campinas: Núcleo de Estudos de Gênero Pagu, n. 21, p. $1-88,2003$

SEIDMAN, Steven. "Introduction." In: Queer Theory/Sociology. Cambridge, MA: Blackwell, 1996. p. 1-25.

SILVA, Marco Aurélio da. "Se manque! Uma etnografia do carnaval do pedaço GLS da Ilha de Santa Catarina". 2003. Dissertação (Mestrado em Antropologia Social) - Programa de Pós-Graduação em Antropologia Social, Universidade Federal de Santa Catarina, Florianópolis, 2003.

SOUZA, Érica Renata de. Necessidade de filhos: maternidade, família e (homo)sexualidade. 2005. Tese (Doutorado em Antropologia Social) - Programa de Pós-Graduação em Antropologia Social, Universidade Estadual de Campinas, Campinas, 2005.

VENCATO, Anna Paula. "Fervendo com as drags": corporalidades e performances de drag queens em territórios gays na llha de Santa Catarina. 2002. Dissertação (Mestrado em Antropologia Social) - Programa de Pós Graduação em Antropologia Social, Universidade Federal de Santa Catarina, Florianópolis, 2002.

WACQUANT, Loïc. Corpo e alma: notas etnográficas de um aprendiz de boxe. Rio de Janeiro: Relume Dumará, 2002.

\begin{abstract}
Methodological-Political-Theorical Reflections on a dying, becoming and being born a Teenage Transvestite

Abstract: From a survey on teens transvestites in the city of Campinas, this paper aims to reflect on theoretical, policitical and methodological issues that involve the theme of gender and sexuality in contemporary society. It will be valued the need to deepen the study on the conventions and social norms than on focusing the individual him/herself. The subjective and bodily question of the researchers in contact with their interlocutors is also approached, and the scientific neutrality in ethonographies involving trans experiences will also be problematized. In addition, the queer thinking and dilemmas that involve the production of the situated knowledge will be contextualized.
\end{abstract}

Key Words: Methodology; Queer Theory; Teenage Transvestite. 